\title{
Short stature as a presenting symptom of attenuated Mucopolysaccharidosis type I: case report and clinical insights
}

\author{
Ana Maria Martins', Kristin Lindstrom², Sandra Obikawa Kyosen', Maria Veronica Munoz-Rojas ${ }^{3}$, \\ Nathan Thibault ${ }^{3}$ and Lynda E. Polgreen ${ }^{4^{*}}$
}

\begin{abstract}
Background: Mucopolysaccharidosis type I (MPS I) results in significant disease burden and early treatment is important for optimal outcomes. Recognition of short stature and growth failure as symptoms of MPS I among pediatric endocrinologists may lead to earlier diagnosis and treatment.

Case presentation: A male patient first began experiencing hip pain at 5 years of age and was referred to an endocrinologist for short stature at age 7 . Clinical history included recurrent respiratory infections, sleep apnea, moderate joint contractures, mild facial dysmorphic features, scoliosis, and umbilical hernia. Height was more than -2 SD below the median at all time points. Growth velocity was below the 3rd percentile. Treatment for short stature included leuprolide acetate and recombinant human growth hormone. The patient was diagnosed with MPS I and began enzyme replacement therapy with laronidase at age 18.

Conclusions: The case study patient had many symptoms of MPS I yet remained undiagnosed for 11 years after presenting with short stature. The appropriate path to MPS I diagnosis when patients present with short stature and/or growth failure plus one or more of the common signs of attenuated disease is described. Improved awareness regarding association of short stature and growth failure with attenuated MPS I is needed since early identification and treatment significantly decreases disease burden.
\end{abstract}

Keywords: MPS I diagnosis, MPS I signs and symptoms, Growth delay, Physician awareness, Early diagnosis, Short stature

\section{Background}

Mucopolysaccharidosis type I (MPS I) is a life-threatening, autosomal recessive disease caused by deficiency of $\alpha$-L-iduronidase (IDUA), a lysosomal enzyme responsible for metabolizing the glycosaminoglycans (GAGs) dermatan and heparan sulfate [1]. MPS I has an estimated incidence of $1 / 100,000$ live births with a spectrum of phenotypes that range from severe (Hurler syndrome) to attenuated (Hurler-Scheie and Scheie syndromes) disease, depending on neurocognitive involvement and the rate of disease progression [2-4].

\footnotetext{
* Correspondence: Ipolgreen@labiomed.org

${ }^{4}$ Los Angeles Biomedical Research Institute at Harbor-UCLA Medical Center, 1124 West Carson Street, Liu Research Building, Torrance, CA 90502, USA Full list of author information is available at the end of the article
}

MPS I results in significant disease burden, disability, and premature death from respiratory and cardiac disease if left untreated, as well as neurodegeneration in the severe phenotype [2]. Treatment options include enzyme replacement with laronidase (recombinant human IDUA; Aldurazyme ${ }^{\circ}$ ) for patients with attenuated MPS I [5-8] and hematopoietic stem cell transplantation (HSCT), with or without laronidase, for patients with severe MPS I [9-13]. Treatment outcomes depend on phenotype and age at initiation of treatment $[6,14,15]$. Early treatment, prior to irreversible damage, can delay, stabilize, or prevent disease, and is associated with substantially improved patient outcomes [5, 6, 10, 16-22]. Unfortunately, there may be considerable delays in the diagnosis of MPS I, especially for patients with attenuated disease [16, 23-25]. In a study of the diagnostic 
history of MPS I patients, approximately $20 \%$ of a population of 60 patients with attenuated MPS I had delays of 5 years or longer in diagnosis, and consulted between 4 and 5 specialists before receiving an MPS I diagnosis [25]. Similarly, for 18 patients with MPS I (13 of whom had attenuated disease) whose symptoms were noted at 18 months, the mean age at biochemical diagnosis was 75 months [26]. While pilot programs for MPS I NBS are in progress around the world [27], they are not universally available, and diagnostic delay persists. There has been no significant improvement in reducing the delay in diagnosis of MPS I as of 2017 [28]. Thus, it remains likely that children with undiagnosed MPS I will be referred to specialists, including endocrinologists, for their care, and awareness of the early clinical signs and symptoms remains important.

Short stature and skeletal sequelae known as dysostosis multiplex are key features among patients with MPS I [15, 24, 29-31], but MPS may be under recognized in patients presenting with short stature, particularly in patients with attenuated disease. Regardless of age and gender, children with MPS have severely disordered growth with percentile values for both longitudinal and transversal parameters (e.g., body length, trunk length, lower extremity length, shoulder breadth, and hip breadth) much lower than reference chart norms [32,33].

Children with short stature (height less than 2 standard deviations below the mean, i.e., near the third percentile) and/or growth failure (growth rate below age-appropriate growth velocity) are often referred to pediatric endocrinologists $[34,35]$. While there are multiple monogenic causes of short stature [35], attenuated MPS I should be considered in the differential diagnosis of patients with growth retardation in conjunction with any of the signs and symptoms of MPS I (Table 1), joint contractures, (particularly of hands, with claw hand deformity, although other joints can be affected), carpal tunnel syndrome (with

Table 1 Common presenting/early symptoms in patients with attenuated MPS I [24, 51]

- Growth delay (normal birth weight, but growth failure or short stature)

- Joint contractures (primarily in hands/claw hand deformity), joint pain and stiffness, restricted mobility

- Carpal tunnel syndrome (trigger digits)

- Recurrent hernias (umbilical and/or inguinal)

- Corneal clouding

- Hepatosplenomegaly

- Skeletal abnormalities/dysostosis multiplex (e.g., kyphosis, scoliosis, hip dysplasia, flattened vertebral bodies, oar-shaped ribs, short thickened clavicles, bullet-shaped phalanges, dysplastic femoral heads, flattened acetabula, coxa valga and genu valgum deformities)

- Ear/nose/throat symptoms (recurrent ear infections, noisy breathing

sleep apnea, enlarged tongue, hearing loss)

- Heart murmur (valve abnormalities)

- Surgical history of multiple hernia repairs, PE tubes, tonsillectomy, adenoidectomy

All symptoms may not be present in the same patient, but are usually progressive. See Fig. 2 for the path to diagnosis trigger digits), umbilical and inguinal hernias, corneal clouding, hepatosplenomegaly, frequent respiratory infections, sleep apnea, cardiac valve abnormalities, and extensive surgical history. The constellation of radiologic abnormalities of ribs, extremities and spine known as dysostosis multiplex are more pronounced in severe MPS I but can develop in patients with attenuated disease at a later age. However, even patients with severe MPS I are still misdiagnosed and treated for other disorders, such as rickets [36], while patients with attenuated disease can go undiagnosed or misdiagnosed [37, 38].

A real-world case report is presented to highlight the existence of undiagnosed MPS I patients in pediatric endocrinology clinics, and describe the appropriate path to MPS I diagnosis when patients present with short stature and/or growth failure plus one or more of the common signs of attenuated disease as described in Table 1 and Fig. 3.

\section{Case presentation}

A male patient first began experiencing hip pain at 5 years of age and was diagnosed with bilateral Legg-Calve-Perthes disease by an orthopedic surgeon (see Table 2 Timeline). The patient was not tested for juvenile idiopathic arthritis. The patient experienced recurrent upper airway tract infections during childhood and was hospitalized multiple times between 5 and 7 years of age for wheezing. He was first seen by a pediatric endocrinologist at 7 years of age due to his short stature, was treated with leuprolide acetate (3.75 mg/month) between the ages of 13 and 16 years, and recombinant human growth hormone $(0.1 \mathrm{UI} / \mathrm{kg} /$ day), although the patient was not labeled as growth hormone deficient (GHD), between 14 and 18 years of age. Longitudinal growth curves and growth velocity for the patient between the ages of 10 and 21 are shown in Figs. 1 and 2. Height was more than -2 SD below the median at all time points. Growth velocity was below the 3rd percentile prior to starting growth hormone. Final height of $159 \mathrm{~cm}$ was reached at 20 years of age.

The patient experienced sleep apnea throughout his teenage years, and at 17 years 9 months of age was referred to a metabolic disease center by a pneumologist (pulmonologist) who had seen the patient and suspected MPS. Upon examination, the patient was found to have moderate joint contractures, mild facial dysmorphic features (coarsening of features), scoliosis, and an umbilical hernia. His height at examination was $154 \mathrm{~cm}$, with a z-score of -2.94 . Weight was $43.7 \mathrm{~kg}$, and head circumference was $56.5 \mathrm{~cm}$. Alpha-iduronidase activity on dried blood spot testing was $0.62 \mu \mathrm{mol} / \mathrm{L} / \mathrm{h}$ (normal reference range 2.5-16.7), and genotype analysis revealed 2 pathogenic IDUA missense variants, c.1148G $>$ A (p.R383H) and c.1598C > G (p.P533R), confirming the 
Table 2 Timeline of assessments, diagnoses and treatment

\begin{tabular}{llll}
\hline Patient age & Symptom(s) & Assessments/diagnoses & Treatment(s) \\
\hline 5-7 years & $\begin{array}{l}\text { Hip pain, recurrent respiratory } \\
\text { infections }\end{array}$ & $\begin{array}{l}\text { Orthopedist assessment and diagnosis of } \\
\text { bilateral Legg-Calve-Perthes disease }\end{array}$ & unknown \\
7-18 years & $\begin{array}{l}\text { Short stature: see Figs. 1 and 2 } \\
\text { Pediatric endocrinologist assessment }\end{array}$ & $\begin{array}{l}\text { Leuprolide acetate (3.75 mg/month) } \\
\text { ages 13-16 } \\
\text { Growth hormone (0.1UI/kg/day) ages 14-18 }\end{array}$ \\
& $\begin{array}{l}\text { Short stature, moderate joint } \\
\text { contractures, mild facial dysmorphic } \\
\text { features (coarsening of features), } \\
\text { scoliosis, and an umbilical hernia }\end{array}$ & $\begin{array}{l}\text { Referred to metabolic disease center by } \\
\text { treating pulmonologist. } \\
\text { enzyme activity screening for MPS I positive; } \\
\text { genetic analysis positive for MPS I }\end{array}$ & $\begin{array}{l}\text { Enzyme replacement therapy with } \\
\text { laronidase (weekly 0.58 mg/kg infusions) } \\
\text { initiated }\end{array}$ \\
& & &
\end{tabular}

diagnosis of MPS I. The patient began ERT with laronidase $(0.58 \mathrm{mg} / \mathrm{kg} /$ week $)$ at age 18 .

\section{Discussion and conclusions}

The case study demonstrates that endocrinologists may not consider MPS I in cases of short stature, even when there are signs and symptoms suggestive of MPS I. Red-flag signs and symptoms for attenuated MPS I (Table 1) exist in the absence of parameters indicating juvenile idiopathic arthritis [39, 40]. The case presentation highlights the diagnostic journey of a patient with attenuated MPS I and short stature followed for over 10 years in a pediatric endocrinology clinic. A strength of this case is the duration of care and longitudinal growth data, although in some instances, assessments and clinical management information were unavailable. This patient had many of the signs and symptoms of attenuated MPS I, yet was not diagnosed until nearly 11 years after presenting to the pediatric endocrinologist with short stature. While not all of the signs listed in Table 1 may be apparent at the initial patient presentation to the endocrinologist, they are likely to develop over time when untreated, or be documented in patient clinical records and history. It is important to note that assessment of bone age in children with growth delay is typically done with an X-ray of the left hand and wrist; thus, pediatric endocrinologists are ideally situated to identify early phalangeal abnormalities (i.e., bullet shaped phalanges) typical of MPS I. A path to MPS I diagnosis when indicating signs are present is shown in Fig. 3.

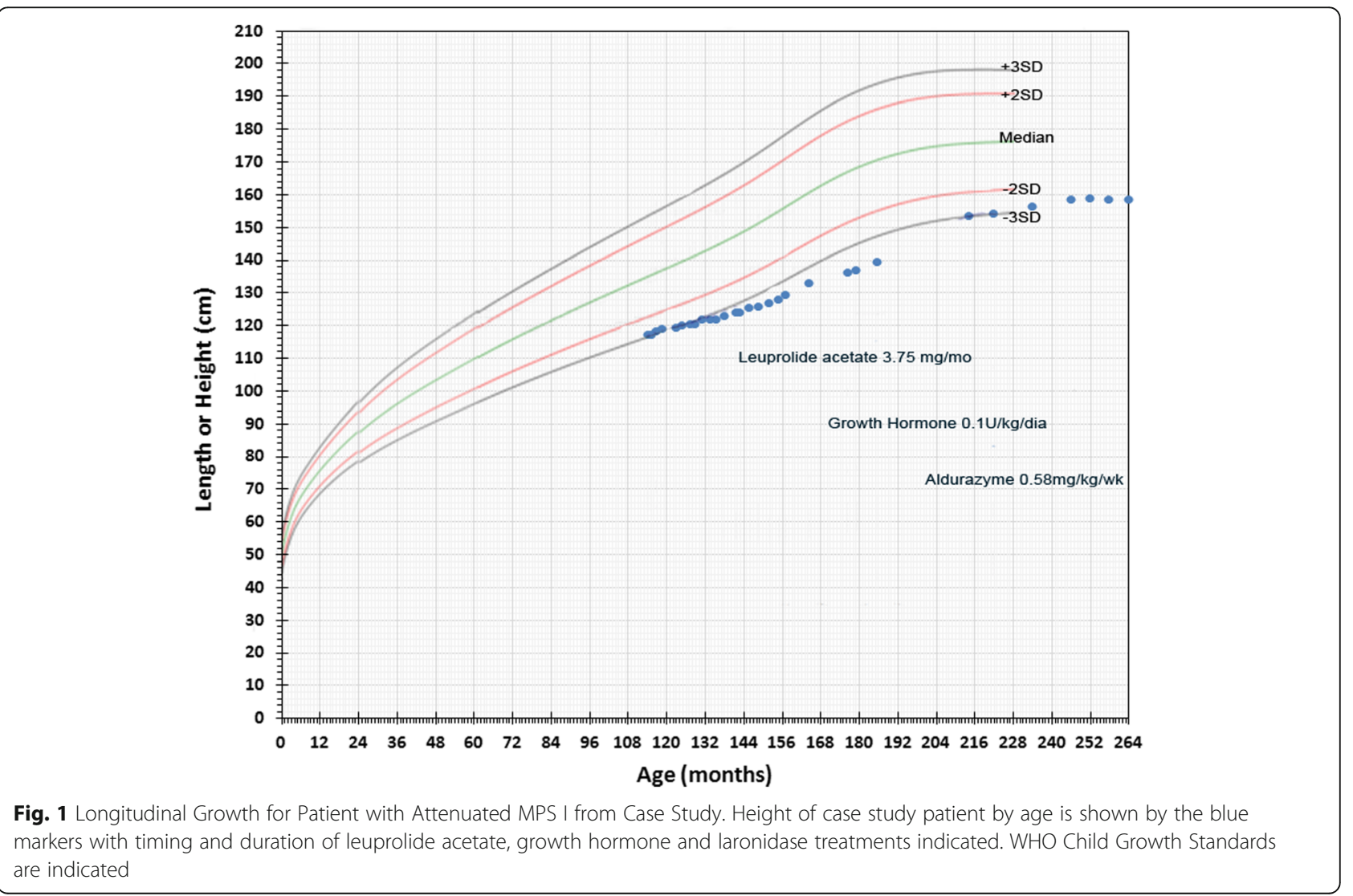




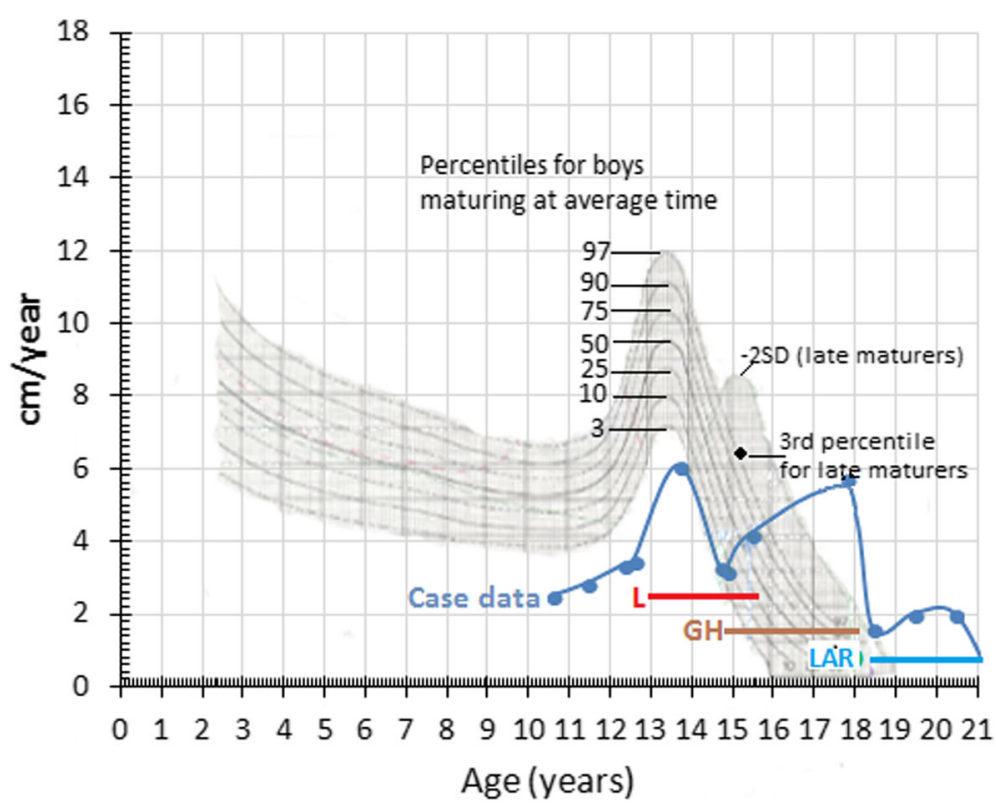

Fig. 2 Growth Velocity of Patient with Attenuated MPS I from Case Study Relative to Growth Standards. Growth velocity by age is shown by the blue markers with timing and duration of leuprolide acetate (L), growth hormone $(\mathrm{GH})$ and laronidase $(\mathrm{LAR})$ treatments indicated. Treatment doses are the same as shown in Fig. 1. Percentiles for boys maturing at average time or for late maturers are shown as adapted from Tanner JM and Davies PS. Clinical longitudinal standards for height and height velocity for North American children [50]

There is considerable overlap of presenting symptoms among the MPS disorders, therefore, screening identified in Fig. 3 should take into account other MPS disorders where short stature is common. Upon consideration of an MPS disorder, a urine GAG (uGAG) test (that may include analyses to determine abnormal GAG pattern, such as electrophoresis or tandem mass spectrometry) can determine the presence of lysosomal storage material. Results of the uGAG test as indicated in Fig. 3 can warrant referral to a geneticist or metabolic disease specialist, who can initiate appropriate enzyme and genetic testing to confirm or rule out an MPS diagnosis. Several

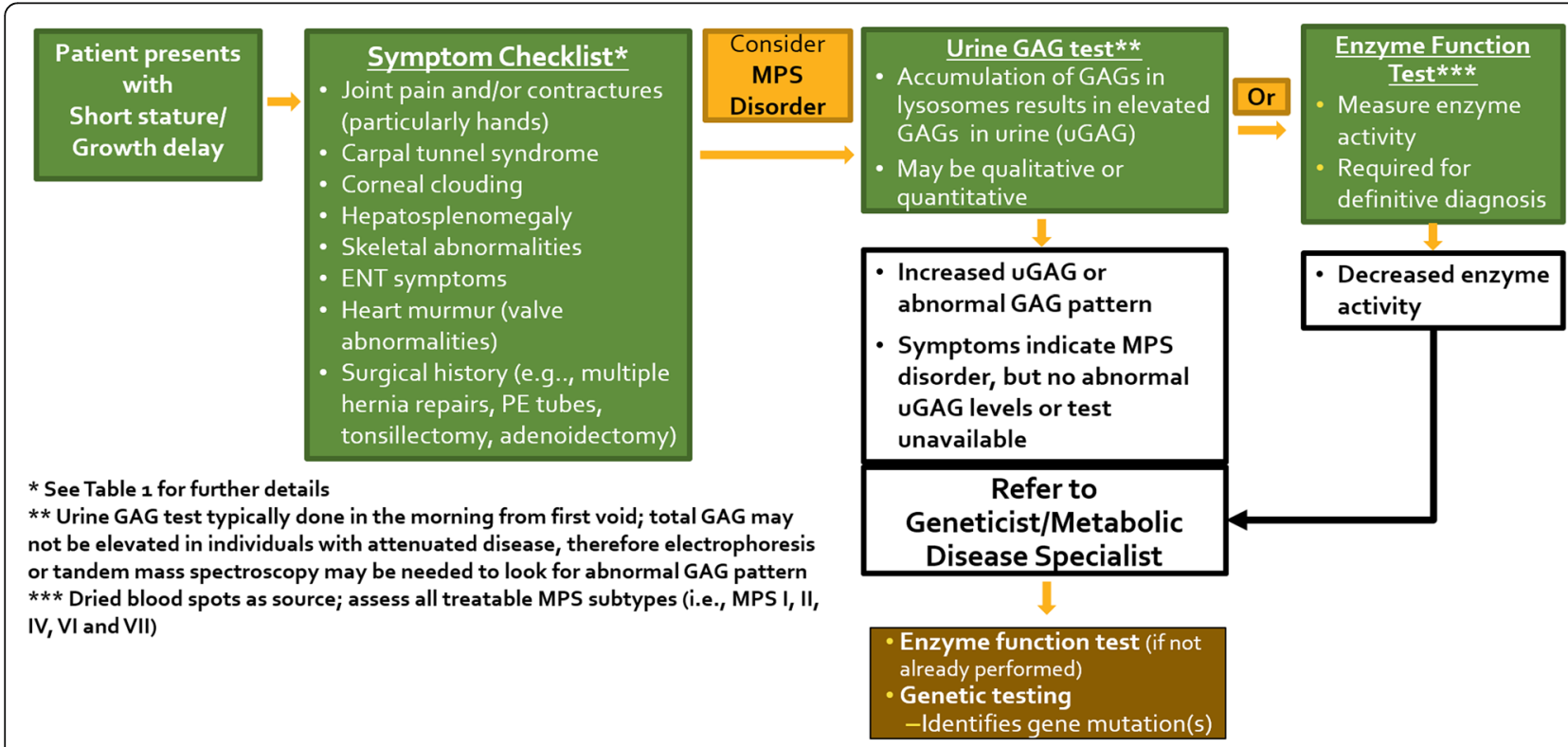

Fig. 3 Symptom Checklist and Path to MPS I Diagnosis. The algorithm describes the key symptoms of MPS I and the pathway of diagnostic tests for a patient presenting with short stature or growth delay 
barriers can exist for appropriate referrals of pediatric patients to metabolic specialists and geneticists, including cost and insurance, wait times, and location [41, 42] and improvements in accessibility for lysosomal storage disease assays may be needed [43].

Studies suggest that increased awareness for endocrinologists may be helpful to highlight the possibility of attenuated MPS in patients presenting with short stature $[37,38]$. In a retrospective assessment of outpatient medical records of patients with short stature of unknown etiology in a pediatric endocrinology service, follow-up screening of 23 patients revealed previously undiagnosed MPS in 3 patients [37]. In another study, 135 physicians with expertise in pediatrics and endocrinology from seven countries (United States, Canada, Italy, Germany, Spain, Mexico, and Brazil) participated in a blinded review of cases for pediatric or adolescent patients with MPS I [38]. Depending on the case reviewed, only $22 \%$ to $58 \%$ of physicians took steps towards a correct MPS I diagnosis. Juvenile idiopathic arthritis was the most common incorrect diagnosis made. A key distinction in the diagnosis of MPS I is the absence of biochemical parameters diagnostic of juvenile idiopathic arthritis. While algorithms exist that include MPS I in the differential diagnosis of juvenile arthritis for pediatric rheumatologists [39, 40], growth specialists and endocrinologists may be among the physicians encountering individuals with undiagnosed MPS disorders, and similar guidelines could prove helpful for recognizing the red-flag signs and symptoms of MPS I and other MPS disorders. A proposed algorithm that includes short stature as a presenting sign in attenuated MPS I has recently been published [44].

The mechanism behind short stature in patients with MPS I is not completely known, but is most likely a secondary characteristic resulting from structural, metabolic, and endocrine abnormalities. Structurally, skeletal abnormalities limit longitudinal growth and final height, but alone cannot explain short stature in patients with MPS I. Pituitary and thyroid dysfunction, GHD, precocious puberty, and pubertal failure have all been reported in patients with MPS I [32, 45]. However, it is important to note that in the absence of GHD, hGH treatment of patients with MPS has not been proven to be effective.

Enzyme replacement therapy with laronidase has resulted in increased growth velocity in pediatric patients [46], particularly in prepubescent children with MPS I [20]. In sibling studies, improved musculoskeletal outcomes were noted in the younger sibling who began ERT in infancy $[5,18,19]$. Retrospective studies indicate that early initiation of laronidase can stabilize existing skeletal disease, and prevent or delay clinical manifestations if initiated prior to symptom onset $[5,19-22]$.
Patients with attenuated MPS I that were less than 10 years of age at treatment initiation remained closer to age-matched norms for several disease parameters, including height, compared with patients that were $\geq 10$ years of age at the start of treatment [22]. There is disagreement regarding the benefits of administration of recombinant human growth hormone, and this is an area of active study [47].

In summary, short stature is a common presenting sign of attenuated MPS I, and may be the symptom that drives clinical care in these patients [36, 48, 49]. Since pediatric endocrinologists are typically the first physician to whom patients with short stature are referred [35], they can play a pivotal role in improving the health and quality of life of patients with attenuated MPS I. Early diagnosis of MPS I and initiation of treatment is critically important as it improves patient outcomes and reduces disease burden $[5,6,8,19,22]$. MPS I should be considered in any patient with short stature and/or growth failure plus one or more of the common signs described in Table 1. The path to diagnosis (Fig. 2) includes urine GAG test, referral to geneticist (or metabolic disease specialist), and appropriate enzyme and genetic testing. Improving the ability of pediatric endocrinologists to recognize the disease manifestations of MPS I can lead to earlier diagnosis and treatment for individuals with MPS I.

\section{Abbreviations \\ GAG: Glycosaminoglycans; GHD: Growth hormone deficient; hGH: Human growth hormone; HSCT: Hematopoeitic stem cell transplant; IDUA: a-L- iduronidase; MPS I: Mucopolysaccharidosis type l; UGAG: Urinary glycosaminoglycans}

\section{Acknowledgments}

The authors thank the individual and their family whose case was presented in this manuscript.

\section{Funding}

Funding was provided by Sanofi Genzyme. Patrice C. Ferriola (KZE

PharmAssociates, LLC) provided assistance in preparation of the manuscript and was funded by Sanofi Genzyme.

Availability of data and materials

De-identified patient data are available upon request.

\section{Authors' contributions}

AMM and SK provided patient data; LP, KL, AMM and SK were involved in assessing and interpreting data; MVMR and NT initiated the study, and all authors participated in manuscript development and writing. All authors read and approved the final manuscript.

\section{Author's information}

Not applicable.

\section{Ethics approval and consent to participate}

The Universidade Federal de São Paulo, Ethics Committee, São Paulo, Brazil provided approval for use of the case study medical records for retrospective studies (CEP-UNIFESP \#2007/11).

\section{Consent for publication}

The patient, who was over 18 at the time of manuscript preparation, provided written consent for use of data in the publication. 


\section{Competing interests}

- LP received research support from Sanofi Genzyme, Shire, and Horizon. Received research grants from the MPS1 Foundation and NIH.

- AMM received grants and speaker honoraria from Sanofi Genzyme.

- SK received Travel Grants from Sanofi Genzyme

- MVMR and NT are employees of Sanofi Genzyme

- $\mathrm{KL}$ received fees from Biomarin and Alexion for lectures

\section{Publisher's Note}

Springer Nature remains neutral with regard to jurisdictional claims in published maps and institutional affiliations.

\begin{abstract}
Author details
'Universidade Federal de São Paulo, São Paulo, Brazil. Phoenix Children's Hospital, Phoenix, AZ, USA. ${ }^{3}$ Sanofi Genzyme, Cambridge, MA, USA. ${ }^{4}$ Los Angeles Biomedical Research Institute at Harbor-UCLA Medical Center, 1124
\end{abstract} West Carson Street, Liu Research Building, Torrance, CA 90502, USA.

Received: 11 July 2018 Accepted: 23 October 2018

\section{Published online: 12 November 2018}

\section{References}

1. Muenzer J. Overview of the mucopolysaccharidoses. Rheumatology (Oxford). 2012;50(Suppl 5):v4-12.

2. Moore D, Connock MJ, Wraith E, Lavery C. The prevalence of and survival in Mucopolysaccharidosis I: hurler, hurler-Scheie and Scheie syndromes in the UK. Orphanet J Rare Dis. 2008;3:24-30

3. Neufeld E, Muenzer J. The mucopolysaccharidoses. In: Schriver C, Beaudet A, Sly W, Valle DCB, Kinzler K, Vogelstein B, editors. The metabolic and molecular basis of inherited disease. New York: McGraw Hill; 2001. p. 3421-52.

4. Thomas JA, Beck M, Clarke JT, Cox GF. Childhood onset of Scheie syndrome, the attenuated form of mucopolysaccharidosis I. J Inherit Metab Dis. 2010;33(4):421-7.

5. Al-Sannaa NA, Bay L, Barbouth DS, Benhayoun Y, Goizet C, Guelbert N, et al. Early treatment with laronidase improves clinical outcomes in patients with attenuated MPS I: a retrospective case series analysis of nine sibships. Orphanet J Rare Dis. 2015;10(1):131-9.

6. Muenzer J. Early initiation of enzyme replacement therapy for the mucopolysaccharidoses. Mol Genet Metab. 2014;111(2):63-72.

7. Tolar J, Orchard PJ. Alpha-L-iduronidase therapy for mucopolysaccharidosis type I. Biologics. 2008;2(4):743-51.

8. Clarke LA, Wraith JE, Beck M, Kolodny EH, Pastores GM, Muenzer J, et al. Long-term efficacy and safety of laronidase in the treatment of mucopolysaccharidosis I. Pediatrics. 2009;123(1):229-40.

9. Aldenhoven M, Jones SA, Bonney D, Borrill RE, Coussons M, Mercer J, et al. Hematopoietic cell transplantation for mucopolysaccharidosis patients is safe and effective: results after implementation of international guidelines. Biol Blood Marrow Transplant. 2015;21(6):1106-9.

10. Aldenhoven M, Wynn RF, Orchard PJ, O'Meara A, Veys P, Fischer A, et al. Long-term outcome of hurler syndrome patients after hematopoietic cell transplantation: an international multicenter study. Blood. 2015;125(13):2164-72

11. Grewal SS, Wynn R, Abdenur JE, Burton BK, Gharib M, Haase C, et al. Safety and efficacy of enzyme replacement therapy in combination with hematopoietic stem cell transplantation in hurler syndrome. Genet Med 2005;7(2):143-6.

12. Yasuda E, Mackenzie W, Ruhnke K, Shimada T, Mason RW, Zustin J, et al. Molecular genetics and metabolism report long-term follow-up of post hematopoietic stem cell transplantation for hurler syndrome: clinical, biochemical, and pathological improvements. Mol Genet Metab Rep. 2015;2:65-76

13. Eisengart JB, Rudser KD, Tolar J, Orchard PJ, Kivisto T, Ziegler RS, et al. Enzyme replacement is associated with better cognitive outcomes after transplant in hurler syndrome. J Pediatr. 2012;162(2):375-80 e1.

14. Giugliani R. Mucopolysacccharidoses: From understanding to treatment, a century of discoveries. Genet Mol Biol. 2012;35(4 (suppl)):924-31.

15. Muenzer J, Wraith JE, Clarke LA. Mucopolysaccharidosis I: management and treatment guidelines. Pediatrics. 2009;123(1):19-29.
16. D'Aco K, Underhill L, Rangachari L, Arn P, Cox GF, Giugliani R, et al. Diagnosis and treatment trends in mucopolysaccharidosis I: findings from the MPS I registry. Eur J Pediatr. 2012;171(6):911-9.

17. de Ru MH, Boelens JJ, Das AM, Jones SA, van der Lee JH, Mahlaoui N, et al. Enzyme replacement therapy and/or hematopoietic stem cell transplantation at diagnosis in patients with mucopolysaccharidosis type l: results of a European consensus procedure. Orphanet J Rare Dis. 2011;6:55-62.

18. Gabrielli O, Clarke LA, Bruni S, Coppa GV. Enzyme-replacement therapy in a 5-month-old boy with attenuated presymptomatic MPS I: 5-year follow-up. Pediatrics. 2009;125(1):e183-7.

19. Gabrielli O, Clarke LA, Ficcadenti A, Santoro L, Zampini L, Volpi N, et al. 12 year follow up of enzyme-replacement therapy in two siblings with attenuated mucopolysaccharidosis I: the important role of early treatment. BMC Med Genet. 2016;17(1):19.

20. Sifuentes M, Doroshow R, Hoft R, Mason G, Walot I, Diament M, et al. A follow-up study of MPS I patients treated with laronidase enzyme replacement therapy for 6 years. Mol Genet Metab. 2007;90(2):171-80.

21. Laraway S, Breen C, Mercer J, Jones S, Wraith JE. Does early use of enzyme replacement therapy alter the natural history of mucopolysaccharidosis I? Experience in three siblings. Mol Genet Metab. 2013;109(3):315-6.

22. Laraway S, Mercer J, Jameson E, Ashworth J, HensmanDip P, Jones SA. Outcomes of long-term treatment with Laronidase in patients with Mucopolysaccharidosis type I. J Pediatr. 2016;178:219-26 e1.

23. Beck M, Arn P, Giugliani R, Muenzer J, Okuyama T, Taylor J, et al. The natural history of MPS I: global perspectives from the MPS I registry. Genet Med. 2014:16(10):759-65.

24. Vijay S, Wraith JE. Clinical presentation and follow-up of patients with the attenuated phenotype of mucopolysaccharidosis type I. Acta Paediatr. 2005;94(7):872-7.

25. Bruni S, Lavery C, Broomfield A. The diagnostic journey of patients with mucopolysaccharidosis I: a real-world survey of patient and physician experiences. Mol Genet Metab Rep. 2016;8:67-73.

26. Vieira T, Schwartz I, Munoz V, Pinto L, Steiner C, Ribeiro M, et al. Mucopolysaccharidoses in Brazil: what happens from birth to biochemical diagnosis? Am J Med Genet A. 2008;146A(13):1741-7.

27. Parini R, Broomfield A, Cleary MA, De Meirleir L, Di Rocco M, Fathalla WM, et al. International working group identifies need for newborn screening for mucopolysaccharidosis type I but states that existing hurdles must be overcome. Acta Paediatr. 2018

28. Kuiper GA, Meijer OLM, Langereis EJ, Wijburg FA. Failure to shorten the diagnostic delay in two ultra-orphan diseases (mucopolysaccharidosis types I and III): potential causes and implications. Orphanet J Rare Dis. 2018;13(1):2.

29. Morishita K, Petty RE. Musculoskeletal manifestations of mucopolysaccharidoses. Rheumatology (Oxford). 2011;50(Suppl 5):v19-25.

30. Rozdzynska-Swiatkowska A, Jurecka A, Cieslik J, Tylki-Szymanska A. Growth patterns in children with mucopolysaccharidosis I and II. World J Pediatr. 2015;11(3):226-31.

31. Tylki-Szymanska A, Rozdzynska A, Jurecka A, Marucha J, Czartoryska B. Anthropometric data of 14 patients with mucopolysaccharidosis I: retrospective analysis and efficacy of recombinant human alpha-Liduronidase (laronidase). Mol Genet Metab. 2009;99(1):10-7.

32. Polgreen LE, Miller BS. Growth patterns and the use of growth hormone in the mucopolysaccharidoses. J Pediatr Rehabil Med. 2010;3(1):25-38.

33. Rogers DG, Nasomyont N. Growth hormone treatment in a patient with hurler-Scheie syndrome. J Pediatr Endocrinol Metab. 2014;27(9-10):957-60.

34. Barstow C, Rerucha C. Evaluation of short and tall stature in children. Am Fam Physician. 2015;92(1):43-50.

35. Wit JM, Oostdijk W, Losekoot M, van Duyvenvoorde HA, Ruivenkamp CA, Kant SG. Mechanisms In Endocrinology: novel genetic causes of short stature. Eur J Endocrinol. 2016;174(4):R145-73.

36. Ayuk A, Obu H, Ughasoro M, Ibeziako N. Unresolving short stature in a possible case of mucopolysccharidosis. Ann Med Health Sci Res. 2014:4(Suppl 1):S38-42.

37. Franco J, Espinosa G, Garcia F. Screening for mucopolysaccaridoses in patients with short stature of unknown etiology. MGM. 2016;117:S47.

38. Thibault N, Cabral JM, Munoz Rojas MV, Bruni S. Awareness of MPS I Among Pediatric Endocrinologists. 14th International Sumposium on MPS and Rlated Disorders; July14-17; Bonn, Germany 2016. 
39. Cimaz R, Coppa GV, Kone-Paut I, Link B, Pastores GM, Elorduy MR, et al. Joint contractures in the absence of inflammation may indicate mucopolysaccharidosis. Pediatr Rheumatol Online J. 2009;7:18-25.

40. Cimaz R, Vijay S, Haase C, Coppa GV, Bruni S, Wraith E, et al. Attenuated type I mucopolysaccharidosis in the differential diagnosis of juvenile idiopathic arthritis: a series of 13 patients with Scheie syndrome. Clin Exp Rheumatol. 2006;24(2):196-202.

41. Delikurt T, Williamson GR, Anastasiadou V, Skirton H. A systematic review of factors that act as barriers to patient referral to genetic services. Eur J Hum Genet. 2015;23(6):739-45.

42. Beene-Harris RY, Wang C, Bach JV. Barriers to access: results from focus groups to identify genetic service needs in the community. Community Genet. 2007;10(1):10-8

43. Verma J, Thomas DC, Kasper DC, Sharma S, Puri RD, Bijarnia-Mahay S, et al. Inherited Metabolic Disorders: Efficacy of Enzyme Assays on Dried Blood Spots for the Diagnosis of Lysosomal Storage Disorders. JIMD Rep. 2016.

44. Tylki-Szymanska A, De Meirleir L, Di Rocco M, Fathalla WM, Guffon N, Lampe C, et al. Easy-to-use algorithm would provide faster diagnoses for mucopolysaccharidosis type I and enable patients to receive earlier treatment. Acta Paediatr. 2018;107(8):1402-8.

45. Gardner CJ, Robinson N, Meadows T, Wynn R, Will A, Mercer J, et al. Growth, final height and endocrine sequelae in a UK population of patients with hurler syndrome (MPS1H). J Inherit Metab Dis. 2011;34(2):489-97.

46. Kakkis ED, Muenzer J, Tiller GE, Waber L, Belmont J, Passage M, et al. Enzyme-replacement therapy in mucopolysaccharidosis I. N Engl J Med. 2001:344(3):182-8

47. Polgreen LE, Thomas W, Orchard PJ, Whitley CB, Miller BS. Effect of recombinant human growth hormone on changes in height, bone mineral density, and body composition over 1-2 years in children with hurler or hunter syndrome. Mol Genet Metab. 2014;111(2):101-6.

48. Clarke LA, Hollak CE. The clinical spectrum and pathophysiology of skeletal complications in lysosomal storage disorders. Best Pract Res Clin Endocrinol Metab. 2015;29(2):219-35.

49. Gadve SS, Sarma D, Saikia UK. Short stature with umbilical hernia - not always due to cretinism: a report of two cases. Indian J Endocrinol Metab. 2012;16(3):453-6.

50. Tanner JM, Davies PS. Clinical longitudinal standards for height and height velocity for north American children. J Pediatr. 1985;107(3):317-29.

51. Pastores GM, Arn P, Beck M, Clarke JT, Guffon N, Kaplan P, et al. The MPS I registry: design, methodology, and early findings of a global disease registry for monitoring patients with Mucopolysaccharidosis type I. Mol Genet Metab. 2007;91(1):37-47.

Ready to submit your research? Choose BMC and benefit from:

- fast, convenient online submission

- thorough peer review by experienced researchers in your field

- rapid publication on acceptance

- support for research data, including large and complex data types

- gold Open Access which fosters wider collaboration and increased citations

- maximum visibility for your research: over $100 \mathrm{M}$ website views per year

At BMC, research is always in progress.

Learn more biomedcentral.com/submissions 